DOI: https://doi.org/10.47405/mjssh.v6i6.805

\begin{tabular}{|c|c|}
\hline $5=$ & Malaysian Journal of Social Sciences and Humanities (MJSSH) \\
\hline Malaysian Journal of & Volume 6, Issue 6, June 2021 \\
\hline (Mulus SSH & e-ISSN : 2504-8562 \\
\hline & $\begin{array}{l}\text { Journal home page: } \\
\text { www.msocialsciences.com }\end{array}$ \\
\hline
\end{tabular}

\title{
Status Sosioekonomi: Satu Cabaran Penglibatan Pelajar dalam Aktiviti Kokurikulum Sekolah Menengah
}

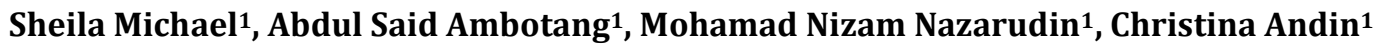 \\ 1Fakulti Psikologi dan Pendidikan, Universiti Malaysia Sabah (UMS) \\ Correspondence: Sheila Michael (ivyandrew@yahoo.com)
}

\begin{abstract}
Abstrak
Kajian ini membincangkan konsep cabaran status sosioekonomi dengan penglibatan pelajar dalam aktiviti kokurikulum sekolah menengah. Sosioekonomi ini merujuk kepada profil ibu bapa yang merangkumi tahap pendidikan, pekerjaan dan pendapatan. Sehubungan itu, kedudukan sosioekonomi merupakan salah satu konstruk yang mempunyai hubung kait dengan penglibatan pelajar dalam aktiviti kokurikulum. Penglibatan pelajar merangkumi tiga aktiviti utama kokurikulum iaitu unit beruniform, kelab dan persatuan, serta sukan dan permainan. Sekolah memainkan peranan utama dalam menggalakkan pelajar menyertai aktiviti kokurikulum. Maka, pelbagai langkah perlu dibuat bagi mengenal pasti permasalahan yang mungkin timbul disebabkan kurangnya penglibatan pelajar dalam aktiviti tersebut. Maka, status sosioekonomi dilihat mempunyai cabaran dengan penglibatan pelajar dalam aktiviti kokurikulum sekolah menengah.
\end{abstract}

Kata kunci: status sosioekonomi, penglibatan pelajar, aktiviti kokurikulum, sekolah menengah

\section{Socioeconomic Status: A Challenge for Student Involvement in Secondary School Co-Curricular Activities}

\begin{abstract}
This article discusses the concept of socioeconomic status relationship with student involvement in secondary school co-curricular activities. This socioeconomic refers to a parent profile which covers the level of education, employment and income. In this regard, socio-economic status is one of the most involved constructs with student involvement in co-curricular activities. Student involvement consists of three main co-curricular activities namely uniformed units, clubs and associations, as well as sports and games. Schools play a key role in encouraging students to participate in co-curricular activities. Hence, various measures should be made to identify problems that may arise due to lack of student involvement in the activity. Thus, socioeconomic status is seen to have a relationship with students' involvement in secondary school co-curricular activities
\end{abstract}

Key words: socioeconomic status, student involvement, co-curricular activities, secondary school 


\section{Pengenalan}

Aktiviti kokurikulum memainkan peranan penting dalam membangunkan kepelbagaian dan fleksibiliti kurikulum pendidikan di seluruh dunia. Selaras dengan itu, ramai pelajar cenderung untuk meneroka dunia dengan memanipulasi persekitaran mereka dan bukannya hanya mengeksploitasi diri mereka dengan buku teks. Lipscomb (2007) mendakwa aktiviti kokurikulum kini menjadi komponen penting di kalangan pelajar sekolah menengah dan memberi mereka keseronokan. Pendapat Feldman dan Matjasko (2005) menyatakan bahawa kegiatan kokurikulum diyakini memberi manfaat kepada pelajar dengan membenarkan mereka mengekspresikan dan meneroka identiti mereka manakala Stearns dan Glennie (2010) mengutarakan persepsi mereka di mana kokurikulum mengembangkan kemampuan praktikal dan kemahiran, dan menjalin hubungan dengan pelajar dan guru lain. Di samping itu, aktiviti kokurikulum juga membolehkan guru lebih memahami pelajar mereka dengan membandingkan prestasi mereka dalam aktiviti rekreasi dengan prestasi mereka dalam akademik formal. Ini dapat dilakukan apabila sekolah dibenarkan menganjurkan kursus dan aktiviti dengan keperluan pelajar serta mempertimbangkan jenis aktiviti kokurikulum yang menarik kepada pelajar apabila membuat penambahbaikan (Himelfarb et al., 2010).

Selain itu, kegiatan kokurikulum memainkan peranan penting untuk kanak-kanak dan remaja (Howie et al., 2010). Ia terdiri daripada penglibatan dalam aktiviti teratur seperti pengakap, bermain sukan untuk sekolah mereka, dan terlibat dalam aktiviti keagamaan. Penyelidikan sebelum ini menunjukkan bahawa kanak-kanak dan remaja yang mengambil bahagian dalam aktiviti kokurikulum lebih cenderung mempunyai hasil pendidikan yang lebih baik, kurang masalah tingkah laku, dan kemahiran prososial yang lebih baik (Fletcher, Nickerson \& Wright 2003; Fredricks \& Eccles, 2008). Sehubungan dengan itu, kegiatan kokurikulum telah memainkan peranan khas dalam kurikulum sekolah kerana mereka bukan sebahagian daripada kurikulum formal dalam kebanyakan sistem pendidikan. Oleh itu, kokurikulum adalah penting untuk merealisasikan dan mampu mengatasi persaingan dan cabaran meluas yang semakin meningkat. Proses perkembangan individu ini perlulah berterusan dan komprehensif tanpa pemisah antara kurikulum dan kokurikulum (Ab. Alim, 2004; Tam Yeow Kwai, 2010).

Kegiatan kokurikulum di sekolah boleh dilaksanakan dengan penglibatan dan penyertaan anggota masyarakat setempat (Surat Pekeliling Ikhtisas Bil. 4/1985). Di satu pihak, pelajar yang mengambil bahagian dalam aktiviti kokurikulum secara berkala lebih cenderung untuk mengembangkan keupayaan mereka untuk meneroka potensi diri dan menyesuaikan sikap, dan sebagai hasilnya, mereka menikmati pencapaian akademik dan bukan akademik yang lebih tinggi (Hansen et al., 2003; Darling, Caldwell \& Smith, 2005; Larson et al., 2006; Bundick, 2011; Metsapelto \& Pulkkine, 2012). Oleh itu, banyak kajian telah dijalankan berkaitan topik kokurikulum ini, dan salah satu tumpuan utama adalah mengenai status sosioekonomi. Selain itu, ianya juga bagi meninjau penglibatan pelajar mengenai aktiviti kokurikulum yang merupakan tunjang kepada keberkesanan program sekolah serta memastikan matlamat kegiatan kokurikulum mampu dicapai secara menyeluruh. Dengan itu, kajian ini akan melihat status sosioekonomi sebagai cabaran penglibatan pelajar dalam aktiviti kokurikulum sekolah menengah.

\section{Status Sosioekonomi}

Status sosioekonomi atau kedudukan ditakrifkan sebagai konsep agregat merangkumi kedua-dua yang berasaskan sumber dan prestij yang berasaskan kelas, iaitu dikaitkan dengan kedudukan kelas sosial kanak-kanak dan dewasa (Stockie, 2009). Ia merupakan ukuran komposit menggabungkan status ekonomi dan sosial serta pembolehubah yang merangkumi kawasan demografi dan persekitaran individu yang lebih luas. Walaupun bagaimanapun, pembolehubah yang paling penting untuk menentukan status sosioekonomi adalah pendapatan, pendidikan dan pekerjaan. Kedudukan sosio ekonomi telah diinterpretasi dan dipengaruhi oleh tiga tradisi sosiologi utama iaitu Marxian, Weberian dan Functionalist (Lynch \& Kaplan, 2000; Aittomaki, 2008). Menurut Karl Marx (Marx \& Engels, 1848/1888; Marx, 1889/1971) dalam Makinen (2010), klasifikasi masyarakat adalah berdasarkan pada hubungan produktif antara manusia dan alam. Dalam istilah yang sangat mudah, kelas sosial muncul 
daripada sistem kapitalis di mana ada individu memiliki harta (kilang, institusi kewangan dan lainlain) dan ada yang tidak. Dalam aspek ini, kelas bawahan (tidak berharta) perlu bekerja untuk kelas pertengahan (yang berharta) untuk menampung kehidupan. Tenaga buruh yang disediakan oleh kelas pertengahan (yang berharta) membolehkan mereka mendapatkan lebihan nilai untuk harta benda mereka. Oleh itu, hubungan yang produktif antara kelas bawahan (tidak berharta) dan kelas pertengahan (yang berharta) menguatkan situasi kelas dan menyebabkan ketidaksamaan dalam kehidupan.

Seterusnya, Wright (1985) mengembangkan kelas sosial Marxian dengan menentukan mereka mengikut eksploitasi. Hubungan kelas adalah berdasarkan pada kawalan dan pengeksploitasian modal yang tidak adil, organisasi dan kemahiran atau kepercayaan. Max Weber (Weber, 1948/1970; Weber, 1968/1978) dalam Makinen (2010) berpendapat bahawa kelas sosial adalah berdasarkan pada kekurangan atau pemilikan barang, kebolehan, dan kemahiran, yang mungkin diguna untuk menjana pendapatan. Mereka dalam kedudukan kelas yang sama dijangka berkongsi peluang hidup yang sama seperti kepercayaan, nilai dan mengikut keadaan. Ahli tradisi Functionalist (Lynch \& Kaplan, 2000) mendakwa bahawa masyarakat memerlukan pengelasan sosial semulajadi dalam sistem kedudukan sosial dan bukannya pada motif, nilai atau aspirasi bagi mereka dalam kedudukan sosioekonomi yang sama. Dalam pandangan Weberian pula, terdapat empat kelas sosial iaitu kelas pekerja (yang melakukan kerja manual); kelas pertengahan (yang berharta); golongan intelek dan pakar (yang tidak berharta); dan kelas yang mendapat keistimewaan melalui harta dan pendidikan (Lynch \& Kaplan, 2000; Wagner et al., 2003; Aittomaki, 2008). Kemudian, petunjuk berasaskan kawasan kedudukan sosioekonomi juga telah diperoleh daripada banci. Pengukuran sosioekonomi berasaskan kawasan termasuk maklumat tentang pengangguran, pemilikan kereta dan rumah. Kajian ini akan memberi tumpuan kepada petunjuk kedudukan sosioekonomi individu.

Pendidikan mungkin merupakan petunjuk utama kedudukan sosioekonomi kerana memudahkan pengukuran, sesuai digunakan untuk semua tanpa mengira status pekerjaan dan kestabilan. Dari perspektif kehidupan, pendidikan mewakili peralihan daripada kedudukan sosioekonomi ibu bapa kepada individu. Walau bagaimanapun, kedudukan sosioekonomi individu mungkin bergantung pada kedudukan sosioekonomi ibu bapa. Di samping itu, kejayaan pendidikan dapat meramalkan kejayaan masa depan: pekerjaan yang lebih baik, pendapatan yang lebih tinggi, kawasan tempat tinggal yang baik dan perumahan yang lebih baik. Kejayaan atau kerjaya pendidikan mungkin mempengaruhi dimensi sosial di mana lulus dari universiti yang terkenal mungkin memberikan hubungan sosial yang berguna iaitu membantu individu untuk mendapatkan pekerjaan dan juga memberi penghargaan sosial secara simbolik (Krieger et al., 1997; Lynch \& Kaplan, 2000).

\section{Penglibatan Pelajar dalam Aktiviti Kokurikulum Sekolah Menengah}

Kajian Barnett (2007) menggambarkan aktiviti kokurikulum dari segi aktiviti iaitu atlit, kelab vokasional, persatuan pelajar, akhbar dan buku tahunan, dan kumpulan minat khusus. Begitu juga, McGaha \& Fitzpatrick (2010) menyifatkan aktiviti kokurikulum sebagai penyertaan dalam aktiviti sekolah dan kejiranan. Fredricks \& Eccles (2006) berpendapat bahawa penyertaan tinggi dalam aktiviti kokurikulum seperti sukan dan kelab sekolah adalah pengisian masa lapang remaja yang produktif. Selain itu, Rubin, Bommer, dan Baldwin (2002) mengkategorikan aktiviti kokurikulum dan meletakkan mereka satu daripada dua kategori iaitu kelab dan organisasi serta pejabat yang diadakan dalam organisasi. Pendekatan kategori juga digunakan oleh Eccles et al. (2003) yang menggambarkan aktiviti kokurikulum dari segi: (1) aktiviti pro-sosial iaitu kehadiran gereja atau aktiviti jenis sukarelawan dan komuniti; (2) aktiviti persembahan iaitu band sekolah, drama dan tarian; (3) kelab sukan (satu atau lebih pasukan sekolah); (4) penglibatan sekolah iaitu persatuan pelajar, kelab pep dan sorak; (5) kelab akademik iaitu debat, bahasa asing, matematik, kelab catur, pesta sains atau tutor dalam mata pelajaran akademik.

Namun begitu. Belikova (2002) berpendapat bahawa aktiviti kokurikulum mengikut bila ia berlaku iaitu dalam masa yang bebas daripada kerja sekolah. Ini sesuai dengan pandangan kedua Christensen et al. (2002) yang menggambarkannya sebagai aktiviti luar kelas, dan Nelson et al. (2002) yang 
menggambarkan aktiviti kokurikulum sebagai pengalaman luar. Penerangan pengkaji lain termasuk Chia (2005) menjelaskan aktiviti kokurikulum adalah usaha bukan akademik atau pengalaman luar kelas (Nelson et al. 2002). Manakala Mahoney, Cairns, dan Farmer (2003) yang menyatakan aktiviti kokurikulum sebagai berstruktur, mencabar dan sukarela. Birzea (2004) pula menggambarkan aktiviti kurikulum dengan menjadi sebahagian daripada kurikulum bukan formal dan mereka berkisar dari lawatan ke pelbagai latar tempat dan institusi, pertukaran sekolah, kerja sukarela, dan organisasi pelajar kepada kelab pelajar dan projek di luar sekolah. Perkara ini mungkin berlaku selepas dan semasa program sekolah dan kedua-duanya masuk dan keluar dari bangunan sekolah.

Walau bagaimanapun, terdapat pandangan yang berbeza mengenai aktiviti kokurikulum. Foster (2008) menekankan bahawa sistem pendidikan di sekolah menawarkan aktiviti kokurikulum di semua peringkat. Selain itu, aktiviti seperti ekstra kurikulum, aktiviti luar bilik darjah dan aktiviti kokurikulum semuanya mempunyai makna yang sama merujuk kepada penyertaan dalam muzik, drama dan perdebatan, dan lain-lain (Emmer, 2010). Kegiatan secara sukarela yang ditawarkan oleh sekolah dan diluluskan secara rasmi dan tidak mempunyai markah tambahan atau gred dalam peperiksaan dianggap sebagai aktiviti kokurikulum (Lunenburg \& Ornstein, 2008). Namun begitu, penyertaan pelajar dalam aktiviti tersebut bergantung pada peluang yang ditawarkan oleh sekolah pada tahap yang berbeza. Pengalaman daripada aktiviti ini membentuk kurikulum alternatif yang membantu membentuk tingkah laku para pelajar dan dimasukkan ke dalam program harian sekolah (Barbieri, 2009). Peluang dalam aktiviti kokurikulum dan sejauh mana penglibatan dalam kegiatan ini dapat mempengaruhi perkembangan holistik individu (Eccles, 2003). Selain itu juga, penglibatan dalam aktiviti ini mungkin bermanfaat dalam pelbagai cara misalnya, ia boleh menggalakkan gaya hidup sihat atau perkembangan personaliti pada peringkat awal. Aktiviti ekstra kurikulum menyediakan pembelajaran yang tidak boleh diajar daripada subjek di dalam bilik darjah dan membantu murid menggunakan pengajaran kelas mereka (Lunnenburg, 2010).

\section{Status Sosioekonomi dengan Penglibatan Pelajar dalam Aktiviti Kokurikulum Sekolah Menengah}

Covay dan Carbonaro (2010) menunjukkan penemuan mereka bahawa tahap pendidikan, pendapatan dan status pekerjaan berkaitan dengan tahap penyertaan yang lebih tinggi dalam aktiviti kokurikulum iaitu konsisten dengan Lareau (2003) dan model konseptual mereka. Beberapa kajian yang menggunakan langkah-langkah yang berkaitan dengan status yang lebih luas menunjukkan corak yang sama. Tambahan pula, status pekerjaan ibu bapa juga didapati sebagai peramal penyertaan dan latihan sukan di kalangan pelajar di Denmark (Toftegaard-Stockel et al., 2011). Status sosioekonomi biasanya diindeks oleh satu atau gabungan penunjuk iaitu tahap pendidikan tinggi, pekerjaan, dan pendapatan (Bornstein et al., 2003). Berdasarkan petunjuk tersebut, status sosioekonomi ibu bapa dianggap berpengaruh dalam penyertaan aktiviti kokurikulum anak-anak kerana dapat menentukan pengetahuan dan sokongan nyata terhadap mereka. Misalnya, ibu bapa yang mempunyai pendapatan dan tahap pendidikan yang tinggi telah menunjukkan sikap positif terhadap penglibatan aktiviti fizikal pelajar (Zinnecker, 1995). Selain itu, pendidikan ibu bapa didapati berkaitan dengan ketidakaktifan aktiviti (Gordon-Larsen et al., 2000). Di samping itu juga, keluarga berpendidikan dilaporkan lebih aktif secara fizikal (Droomers et al., 1998; McVeigh et al., 2004). Namun begitu, pelajar daripada keluarga berpendapatan rendah dianggap mempunyai akses terhad kepada sumber yang boleh menyokong aktiviti fizikal (Sallis et al, 1996). Keluarga yang berkemampuan dijangka lebih mampu menyediakan sokongan kewangan untuk penyertaan aktiviti fizikal pelajar, manakala pelajar di dalam kumpulan sosioekonomi rendah agak kurang berpeluang untuk menyertai aktiviti sukan yang memerlukan pembayaran.

Kesan daripada ketidakseimbangan pendapatan yang semakin meningkat, pengasingan yang semakin meningkat di sekolah dan kawasan kejiranan, kos aktiviti rekreasi yang lebih tinggi dan akses kepada kelengkapan dan pengangkutan yang bervariasi, bersama dengan ibu bapa yang berpengetahuan lebih menghargai nilai penglibatan anak-anak mereka dalam kegiatan ini, merupakan alasan utama di sebalik jurang yang semakin besar dalam peluang dan penyertaan aktiviti (White \& Gager 2007). Putnam (2015) berpendapat apabila jumlah kos aktiviti kokurikulum untuk kanak-kanak keluarga 
Amerika dalam kuartil teratas, pengagihan pendapatan adalah kira-kira 1 hingga 2 peratus daripada pendapatan tahunan mereka, jumlah yang sama untuk keluarga dalam kuartil bawah adalah kira-kira 10 peratus atau lebih. Berdasarkan nombor-nombor ini, kejutannya adalah bahawa setiap kanak-kanak miskin sama sekali mengambil bahagian dalam aktiviti tambahan kurikulum. Pelajar yang mempunyai keluarga berpendapatan rendah kurang aktif dalam aktiviti ekstra kurikulum secara umumnya (Leung et al., 2019). Kesan pendapatan ini adalah benar, kerana pendapatan yang lebih rendah mengekang belanjawan wang yang boleh diperuntukkan untuk aktiviti kokurikulum, sementara pendapatan yang lebih tinggi memiliki kewangan untuk berseronok iaitu dilihat sebagai satu sosiobudaya untuk menggambarkan kekayaan, kuasa dan status, dan akses istimewa ke sumber terhad (de Castro \& de Guzman, 2014). Menariknya, kesan pendapatan terhad kepada penyertaan aktiviti bukan akademik, tetapi bukan penyertaan aktiviti akademik. Ini seolah-olah menunjukkan penglibatan aktiviti akademik yang meluas di kalangan pelajar di seluruh isi rumah dalam pelbagai lapisan kehidupan.

Pendidikan telah dianggap sebagai petunjuk sosioekonomi yang menghasilkan hubungan yang lebih konsisten dengan penyertaan aktiviti fizikal (Gidlow et al., 2006). Kajian terdahulu menyokong pendidikan ibu bapa mempunyai kaitan dengan tahap penglibatan sukan anak-anak mereka iaitu ibu bapa yang berpendidikan tinggi mempunyai anak yang lebih aktif dalam kokurikulum (Cvetkovic et al., 2014). Di samping itu, ibu dengan tahap pendidikan yang tinggi lebih cenderung terlibat dalam tingkah laku mempromosikan kesihatan. Oleh itu, mereka merupakan model yang berpengaruh dalam penglibatan aktiviti fizikal anak mereka (Desai \& Alva, 1998). Leung et al. (2019) mendedahkan kesan positif pendidikan ibu bapa terhadap penyertaan pelajar dalam banyak aktiviti selepas sekolah (khususnya aktiviti akademik dan seni) dan juga dalam kesusasteraan (Bray \& Kwok, 2003; Hjorthol \& Fyhri, 2009). Keseluruhannya, pelajar yang mempunyai ibu bapa atau penjaga yang berpendidikan tinggi cenderung tinggal di kawasan yang lebih padat dan lebih banyak mengambil bahagian dalam aktiviti seni akademik dan budaya tinggi kerana mereka lebih mampu mengakses pusat aktiviti di kawasan tersebut dengan pelbagai jenis aktiviti (Karsten, 2014). Ibu bapa atau penjaga ini mungkin mempunyai jangkaan yang lebih tinggi terhadap anak-anak mereka dan hasilnya mereka akan mengatur anak-anak mereka untuk mengambil bahagian dalam aktiviti tambahan kokurikulum untuk perkembangan masa depan mereka yang menyeluruh (Bray \& Kwok, 2003).

Gracia-Marco et al. (2010) memperlihatkan pembolehubah yang dinilai iaitu pendidikan bapa bagi lelaki; pendidikan dan pekerjaan bapa serta pendidikan ibu untuk perempuan, mempengaruhi penyertaan dalam sukan aktiviti kokurikulum. Regresi secara logistiknya mengesahkan hubungan bebas antara pendidikan bapa dengan penyertaan aktiviti kokurikulum dalam sukan. Pelajar yang mempunyai bapa berpendidikan tinggi (universiti) lebih cenderung untuk melibatkan diri dalam sukan aktiviti kokurikulum daripada bapa mereka mempunyai tahap pendidikan rendah (sekolah rendah). Hasil yang sama turut dilaporkan di Itali (La Torre et al., 2006) dan Hungary (Piko \& Keresztes, 2008). Di samping itu, pendidikan bapa dikaitkan dengan ketidakaktifan pelajar Cina (Li et al., 2006). Ia menunjukkan bahawa strategi untuk meningkatkan penyertaan pelajar dalam sukan juga perlu mengambil kira pengaruh bapa. Walau bagaimanapun, disebabkan pendidikan bapa, dan bukannya ibu, secara bebas dikaitkan dengan penyertaan aktiviti kokurikulum pelajar dalam sukan disebabkan budaya iaitu pendidikan bapa menentukan status sosioekonomi keluarga lebih daripada pendidikan ibu.

Kajian La Torre et al. (2006) mendakwa bahawa aktiviti kokurikulum berkaitan dengan pekerjaan ibu bapa. Pelajar yang bapanya adalah pengurus atau profesional mahupun pekerja pejabat atau pekerja mahir menunjukkan tahap fizikal ekstra kurikulum yang lebih tinggi berbanding pelajar dengan bapanya yang bukan pekerja mahir, menganggur atau bersara. Aktiviti kerja ibu juga sangat mempengaruhi aktiviti fizikal kokurikulum pelajar. Pelajar yang mempunyai ibu yang bukan pekerja mahir atau suri rumahtangga atau penganggur kurang melibatkan diri dalam kokurikulum berbanding ibu yang menjadi pengurus atau profesional mahupun pekerja pejabat atau pekerja mahir. Selain itu, La Torre et al. (2006) menunjukkan tahap pendidikan yang dicapai oleh bapa mempengaruhi aktiviti fizikal pelajar. Pelajar dengan bapa yang tamat pengajian dengan ijazah lebih kerap melibatkan diri dalam aktiviti fizikal kokurikulum dan lebih intensif bapa yang berpendidikan rendah. Tamabahan pula, tahap pendidikan ibu juga mempengaruhi penentu aktiviti fizikal pelajar dan jumlah jam aktiviti fizikal mingguan ekstra kurikulum. Pelajar dengan ibu yang menamatkan pengajian ijazah lebih 
berkemungkinan mengamalkan aktiviti fizikal kurikulum dan menjalankan aktiviti fizikal lebih daripada tiga jam seminggu, berbanding ibu yang mempunyai tahap pendidikan rendah.

Kajian terdahulu mencadangkan penyertaan dalam kokurikulum adalah berbeza mengikut latar belakang keluarga (Lareau 2003; Dumais 2006). Dalam kajian etnografinya yang mendalam, Lareau (2003) mendapati kepentingan perbezaan kelas dalam menentukan cara pelajar menghabiskan masa lapang mereka iaitu pelajar kelas atasan dan kelas pertengahan tidak mempunyai perubahan berjadual dan menghabiskan lebih banyak masa dalam kokurikulum berstruktur, manakala pelajar kelas bawahan dan kelas pekerja, kebanyakannya mengambil bahagian dalam aktiviti tidak berstruktur. Seterusnya, Dumais (2006) menganalisis data yang mewakili negara dan mendapati bahawa status sosioekonomi mempunyai hubungan positif dengan penyertaan aktiviti kokurikulum. Kajian oleh Swanson (2002) menunjukkan korelasi positif yang kuat antara latar belakang keluarga dan penglibatan. Penemuan daripada kajian menunjukkan bahawa pelajar yang berasal daripada keluarga berstatus sosioekonomi pertengahan dan atasan cenderung menunjukkan kadar penyertaan yang lebih tinggi, kerana mereka mempunyai akses yang lebih baik kepada sumber. Malah, keluarga berstatus ekonomi yang lebih tinggi mempunyai penglibatan yang jauh lebih tinggi daripada keluarga berstatus sosioekonomi yang lebih rendah atau pertengahan. Oleh itu, pelajar yang mempunyai keluarga berstatus sosioekonomi rendah akan kehilangan banyak manfaat yang diterima oleh pelajar daripada keluarga berstatus sosioekonomi yang lebih tinggi.

\section{Rumusan}

Kesimpulannya, sosioekonomi didapati memberi cabaran kepada penglibatan pelajar dalam aktiviti kokurikulum. Maka, kajian ini mencadangkan kepada pihak sekolah agar memberi penekanan kepada aspek kedudukan sosioekonomi ibu bapa khususnya pendidikan, pendapatan dan pekerjaan. Hal ini kerana penglibatan aktiviti kokurikulum pelajar bergantung kepada profil ibu bapa. Sehubungan itu, kertas konsep ini diharapkan dapat dijadikan panduan kepada semua pihak termasuklah peringkat jabatan mahupun kementerian Namun begitu, kajian lanjutan dengan meneroka aspek-aspek lain yang turut mempengaruhi penglibatan aktiviti kokurikulum turut dicadangkan bagi mendapat suatu gambaran yang menyeluruh berkaitan dengan faktor-faktor yang mempengaruhi penglibatan pelajar selaras dengan matlamat kokurikulum dan dasar pendidikan negara.

\section{Rujukan}

Ab. Alim, A. R. (2004): Pengurusan Gerak Kerja Kokurikulum. Selangor: Penerbit Oxford Sdn. Bhd. Aittomaki, A. (2008). Social-class inequalities in ill health-the contribution of physical workload.

Barbieri, M. (2009). Extracurricular activities. New York, NY: St.Martin's Press.

Barnett, L. A. (2007). "Winners" and "losers": The effects of being allowed or denied entry into competitive extracurricular activities. Journal of Leisure Research, 39(2), 316-344.

Belikova, L. F. (2002). Students' Attitudes Toward Extracurricular Activity in an Institution of Higher Learning. February 2002. Russian Education \& Society 44(2):73-85.

Bornstein, M. H., Hahn, C., Suwalsky, J. T. D., \& Haynes, O. M. (2003). Socioeconomic status, parenting, and child development: The Hollingshead Four-Factor Index of Social Status and the Socioeconomic Index of Occupations.

Bray, M., \& Kwok, P. (2003). Demand for private supplementary tutoring: conceptual considerations, and socio-economic patterns in Hong Kong. Economics of Education Review, 22, 611-620.

Bundick, M. J. (2011). Extracurricular activities, positive youth development, and the role of meaningfulness of engagement. The Journal of Positive Psychology, 6(1), 57-74.

Christensen, T.E., Fogarty, T.J., \& Wallace, W.A. (2002). The association between directional accuracy and self-efficacy and accounting course performance. Issues in Accounting Education, 17(1) 1-26.

Covay, E., \& Carbonaro, W. (2010). After the bell: Participation in extracurricular activities, 
classroom behavior, and academic achievement. Sociology of Education, 83(1), 20-45.

Cvetkovic, N., Nikolic, D., Pavlovic, L., Djordjevic, N., Golubovic, M., Stamenkovic, S., \& Velickovic, M. (2014). Socio-economic status of parents and their children sports engagement. Facta Universitatis, Series: Physical Education and Sport, 179-190.

Darling, N., Caldwell, L. L., \& Smith, R. (2005). Participation in school-based extracurricular activities and adolescent adjustment. Journal of Leisure Research, 37(1), 51-76.

De Castro, B. V., \& De Guzman, A. (2014). Push and pull factors affecting Filipino students' Shadow Education (SE) participation. January 2010. KEDI journal of educational policy 7(1):43-66.

Desai, S., \& Alva, S. (1998). Maternal Education and Child Health: Is There a Strong Causal Relationship? Demography, 35(1):71-81. [PubMed: 9512911].

Droomers, M., Schrijvers, C. T. M., Van de Mheen, H., et al. (1998). Educational differences in leisure-time physical inactivity: A descriptive and explanatory study. Social Science \& Medicine 47(11): 1665-1676.

Dumais, S. A. (2006) Early Childhood Cultural Capital, Parental Habitus, and Teachers ${ }^{\text {ee }}$ Perceptions. Poetics 34, 2, 83-107.

Eccles, J. (2003). Extracurricular activities and adolescent development. Journal of Social Issues, 59(4),865-889.

Eccles, J. S., Barber, B. L., Stone, M., \& Hunt, J. (2003). Extracurricular activities and adolescent development. Journal of Social Issues, 59, 865-890.

Emmer, R. (2010d). Community service. New York, NY: Rosen Publishing Group.

Feldman, A. \& Matjasko, J. (2005) The Role of School-Based Extracurricular Activities in Adolescent Development: A Comprehensive Review and Future Directions. Review of Educational Research, 75, 159-210.

Fletcher, A.C., Nickerson, P., \& Wright, K.L. (2003). Structured leisure activities in middle childhood: Links to well-being. Journal of Community Psychology, 31, 641-659.

Foster, C. R. (2008). Extracurricular activities in the high school. New York, NY: Read Books.

Fredricks, J. A., \& Eccles, J. S. (2006). Extracurricular involvement and adolescent adjustment: Impact of duration, number of activities, and breadth of participation. Applied developmental science, $10(3), 132-146$.

Fredricks, J. A., \& Eccles, J. S. (2008). Participation in extracurricular activities in the middle school years: Are there developmental benefits for African American and European American youth? Journal of Youth and Adolescence, 37, 1029-1043.

Gracia-Marco, L., Tomàs, C., Vicente-Rodríguez, G., Jiménez-Pavón, D., Rey-López, J. P., Ortega, F. B., \& Moreno, L. A. (2010). Extra-curricular participation in sports and socio-demographic factors in Spanish adolescents: the AVENA study. Journal of Sports Sciences, 28(13), 13831389.

Gidlow, C., Johnston, L. H., Crone, D., Ellis, N., \& James, D. (2006). A systematic review of the relationship between socio-economic position and physical activity. Health Education Journal, 65(4), 338-367.

Gordon-Larsen, P., McMurray, R. G., \& Popkin, B. M. (2000). Determinants of adolescent physical activity and inactivity patterns. Paediatrics, 105(6): e83-e83.

Hansen, D. M., Larson, R. W., \& Dworkin, J. B. (2003). What adolescents learn in organized youth activities: A survey of self-reported developmental experiences. Journal of Research on Adolescence, 13(1), 25-55.

Himelfarb, I., Lac, A., \& Baharav, H. (2014). Examining school-related delinquencies, extracurricular activities, and grades in adolescents. Educational Studies, 40(1), 81- 97.

Hjorthol, R., and Fyhri, A. (2009). Do organized leisure activities for children encourage car-use? Transportation Research Part A, 43(2), 209-218.

Howie, L. D., Lukacs, S. L., Pastor, P. N., Reuben, C. A., \& Mendola, P. (2010). Participation in Activities Outside of School Hours in Relation to Problem Behaviour and Social Skills in Middle Childhood. Journal of School Health, 80(3), 119-125.

Karsten, L. (2014). Middle-class childhood and parenting culture in high-rise Hong Kong: On scheduled lives, the school trap and a new urban idyll. Children's Geographies, 13, 556-570.

Krieger, N., Williams, D. R., \& Moss, N. E. (1997). Measuring social class in US public health research: concepts, methodologies, and guidelines. Annual review of public health, 18(1), 341- 
378.

La Torre, G., Masala, D., De Vito, E., Langiano, E., Capelli, G., \& Ricciardi, W. (2006). Extracurricular physical activity and socioeconomic status in Italian adolescents. BMC Public Health, 6(1), 22.

Lareau, A. (2003). Unequal childhoods. Berkeley: University of California Press.

Larson, R. W., Hansen, D. M., \& Moneta, G. (2006). Differing profiles of developmental experiences across types of organized youth activities. Developmental Psychology, 42(5), 849-863.

Leung, K. Y. K., Astroza, S., Loo, B. P. Y., \& Bhat, C. R. (2019). "An environment-people interactions framework for analysing children's extra-curricular activities and active transport," Journal of Transport Geography, 74(C), 341-358.

Li, M., Dibley, M. J., Sibbritt, D., \& Yan, H. (2006). Factors associated with adolescents' physical inactivity in Xi'an City, China. Medicine and science in sports and exercise, 38(12), 2075-2085.

Lipscomb, S. (2007). Secondary school extracurricular involvement and academic achievement: A fixed effects approach. Economics of Education Review, 26, 463-472.

Lunenburg, F. C. (2010). Extracurricular activities. Schooling, 1(1), 1-4.

Lunenburg, F. C., \& Ornstein, A. O. (2008). Educational administration: Concepts and practices (5th ed). Belmont, CA: Wadsworth/Cengage Learning.

Lynch, J., \& Kaplan, G. (2000). Socioeconomic position. Social epidemiology. New York: Oxford University Press.

Makinen, T. (2010). Trends and explanations for socioeconomic differences in physical activity.

McGaha, V., \& Fitzpatrick, J. (2010). Employment, Academic and Extracurricular Contributors to College Aspirations. Journal of College Admission, 207, 22-29.

McVeigh, J., Norris, S., \& De Wet, T. (2004). The relationship between socio-economic status and physical activity patterns in South African children. Acta Paediatrica, 93(7): 982-988.

Metsäpelto, R. L., \& Pulkkinen, L. (2012). Socioemotional behaviour and school achievement in relation to extracurricular activity participation in middle childhood. Scandinavian Journal of Educational Research, 56(2), 167-182.

Nelson, I. T., Vendrzyk, V., Quirin, J. J., \& Allen, R. D. (2002). No, the Sky Is Not Falling: Evidence of Accounting Student Characteristics at FSA Schools, 1995-2000. August 2002. Issues in Accounting Education, 17(3):269-287.

Piko, B. F., \& Keresztes, N. (2008). Sociodemographic and socioeconomic variations in leisure time physical activity in a sample of Hungarian youth. International Journal of Public Health, 53(6), 306-310.

Putnam, R. (2015). Our kids. The American dream in crisis. New York: Simon \& Schuster.

Rubin, R. S., Bommer, W. H., \& Baldwin, T. (2002). Using extracurricular activity as an indicator of interpersonal skill: Prudent evaluation or recruiting malpractice? November 2002. Human Resource Management, 41(4):441 - 454.

Sallis, J. F., Zakarian, J. M., Hovell, M. F., et al. (1996). Ethnic, socioeconomic, and sex differences in physical activity among adolescents. Journal of Clinical Epidemiology, 2(49): 125-134.

Stockie, M. L. (2009). The relationship between socioeconomic status and physical activity among adolescents. Thesis and Dissertations (Comprehensive). Paper 952.

Swanson, C. B. (2002). Spending Time or Investing Time? Involvement In High School Curricular and Extracurricular Activities as Strategic Action. November 2002. Rationality and Society, 14(4):431-471.

Tam Yeow Kwai (2010): Pengurusan Kokurikulum. Kuala Lumpur: Kumpulan Budiman Sdn. Bhd.

Toftegaard-Støckel, J., Nielsen, G. A., Ibsen, B., \& Andersen, L. B. (2011). Parental, socio and cultural factors associated with adolescents' sports participation in four Danish municipalities. Scandinavian Journal of Medicine \& Science in Sports, 21(4), 606-611.

Wagner, A., Simon, C., Evans, A., Ducimetiere, P., Bongard, V., Montaye, M., \& Arveiler, D. (2003). Physical activity patterns in 50-59 years men in France and Northern Ireland. Associations with socio-economic status and health behaviour. European Journal of Epidemiology, 18(4), 321-329.

White, A. M., \& Gager, C. T. (2007). Idle hands and empty pockets? Youth involvement in extracurricular activities, social capital, and economic status. Youth and Society, 39(1), 75-111.

Wright, Erik Olin (1985). Classes. London: Verso. 
Zinnecker J (1995) The cultural modernisation of childhood. In: Chisholm L, Büchner P, Krüger HH, et al. (eds) Growing Up in Europe: Contemporary Horizons in Childhood and Youth Studies. Berlin: Walter de Gruyter, pp. 85-94. 